University of Wollongong

Research Online

Faculty of Social Sciences - Papers (Archive) Faculty of Arts, Social Sciences \& Humanities

$1-1-2017$

EEG differences between eyes-closed and eyes-open resting remain in healthy ageing

Robert J. Barry

University of Wollongong, rbarry@uow.edu.au

Frances M. De Blasio

University of Wollongong, francesd@uow.edu.au

Follow this and additional works at: https://ro.uow.edu.au/sspapers

Part of the Education Commons, and the Social and Behavioral Sciences Commons

Research Online is the open access institutional repository for the University of Wollongong. For further information contact the UOW Library: research-pubs@uow.edu.au 


\title{
EEG differences between eyes-closed and eyes-open resting remain in healthy ageing
}

\author{
Abstract \\ In young adults and children, the eyes-closed (EC) resting state is one of low EEG arousal, with the change \\ to eyes-open (EO) primarily involving an increase in arousal. We used this arousal perspective to interpret \\ $\mathrm{EC} / \mathrm{EO}$ differences in healthy young and older adults. EEG was recorded from 20 young (Mage=20.4years) \\ and 20 gender-matched older (Mage=68.2years) right-handed adults during two 3 min resting conditions; \\ EC then EO. Older participants displayed less delta and theta, some reduction in alpha, and increased \\ beta. Global activity in all bands reduced with opening the eyes, but did not differ with age, indicating that \\ the energetics of EEG reactivity is maintained in healthy ageing. However, older adults had more focal \\ changes than young adults, particularly in beta, suggesting the mobilisation of additional localised \\ resources. This maintained reactivity, and heightened focal activity, may underlie preserved performance \\ levels in healthy ageing.

\section{Disciplines} \\ Education | Social and Behavioral Sciences

\section{Publication Details} \\ Barry, R. J. \& De Blasio, F. M. (2017). EEG differences between eyes-closed and eyes-open resting remain \\ in healthy ageing. Biological Psychology, 129 293-304.
}


EEG Differences between Eyes-Closed and Eyes-Open Resting Remain in Healthy Ageing

Robert J. Barry*, Frances M. De Blasio

Brain \& Behaviour Research Institute and School of Psychology, University of Wollongong, Wollongong, NSW, Australia.

This research did not receive any specific grant from funding agencies in the public, commercial, or not-for-profit sectors.

*Corresponding author

Ph. +61242214421

Fax. +61242214421

E-mail.robert_barry@uow.edu.au

Address: School of Psychology, University of Wollongong, Wollongong NSW 2522, Australia. 


\begin{abstract}
In young adults and children, the eyes-closed (EC) resting state is one of low EEG arousal, with the change to eyes-open (EO) primarily involving an increase in arousal. We used this arousal perspective to interpret EC/EO differences in healthy young and older adults. EEG was recorded from 20 young $\left(M_{\text {age }}=20.4\right.$ years $)$ and 20 gender-matched older $\left(M_{\text {age }}=68.2\right.$ years) right-handed adults during two 3 min resting conditions; EC then EO. Older participants displayed less delta and theta, some reduction in alpha, and increased beta. Global activity in all bands reduced with opening the eyes, but did not differ with age, indicating that the energetics of EEG reactivity is maintained in healthy ageing. However, older adults had more focal changes than young adults, particularly in beta, suggesting the mobilisation of additional localised resources. This maintained reactivity, and heightened focal activity, may underlie preserved performance levels in healthy ageing.
\end{abstract}

Keywords: Normal ageing; Resting EEG; Eyes Open vs. Eyes Closed; Arousal/Activation; Clinical screening tool; EEG reactivity. 


\section{Introduction}

\subsection{EEG arousal and activation}

The defining characteristic of electroencephalographic (EEG) alpha is that the dominant synchronisation reflected in eyes-closed (EC) conditions is desynchronised or blocked in eyes-open (EO) conditions (Adrian and Matthews, 1934; Berger, 1933; Chapman et al., 1962; Gale et al., 1971; Glass and Kwiatkowski, 1970; Jasper, 1936; Legewie et al., 1969; Smith, 1938; Volavka et al., 1967). This alpha desynchronisation probably reflects increased visual system activity mediated by the Reticular Activating System (Gale et al., 1971; Hardle et al., 1984; Volavka et al., 1967), or widespread cortical and thalamo-cortical interactions, aiding information processing (Fisch, 1999; Gevins et al., 1997; Klimesch, 1999) by activating the entire cortex (Başar and Schürmann, 1999).

In a series of studies with a particular focus on the link between arousal and alpha, we applied Pribram and McGuinness' (1975) distinction between arousal and activation, defining "arousal" as the current energetic level of the organism, and "activation" as the mobilisation of energy needed for performance. Skin conductance level (SCL) has a long history of use as an arousal measure in autonomic studies (e.g., in the context of the Orienting Reflex: Barry, 2004; Barry and Sokolov, 1993), and we initially developed our arousal/activation energetics concepts using this autonomic measure. In a series of studies we linked current arousal levels to physiological phasic response amplitudes, and task-related activation to behavioural performance measures (VaezMousavi et al., 2007a, 2007b, 2009). These links are shown schematically in Figure 1. From this perspective, current arousal level acts as an amplifier of physiological responses, while task-related activation reduces reaction time and errors, serving to enhance behavioural performance.

Fig. 1 about here

We first linked SCL to global EEG alpha power in a resting state study in children 
(Barry et al., 2004a), where higher SCL was associated with lower levels of global alpha power across the scalp. We replicated this in children with $\mathrm{AD} / \mathrm{HD}$, and in age- and gendermatched controls (Barry et al., 2009c). We also manipulated arousal with caffeine, and found that EC resting global alpha power decreased and SCL increased with caffeine in young adults (Barry et al., 2005, 2008) and in children (Barry et al., 2009b), confirming the inverse alpha/arousal nexus. Subsequently, Barry et al. (2007) found that EO in young adults was associated with increased SCL and a global reduction in alpha power compared with EC, leading us to equate energetics differences associated with EC/EO with activation. Barry et al. (2009a) confirmed these EC/EO findings in children. The relation between these independent variables was explored by Barry et al. (2011) in young adults. Caffeine and opening of the eyes were found to have additive effects on both the arousal-defining SCL increase and the decrease in global alpha amplitude.

These eight separate EEG/SCL studies provide a solid base for our conceptualisation of global alpha as an inverse marker of arousal, as indicated on the vertical axis of Figure 1. An important measurement characteristic of alpha as the EEG marker of arousal derives from our concept of arousal-as-amplifier. This "amplifier" concept suggests that a pure arousal shift in cortical source activity will produce an amplified increase/decrease in band activity across the scalp - an EEG arousal change at any electrode will be proportional to the existing band level at that electrode. Alpha alone meets this criterion for an EEG arousal measure compatible with neuroanatomical models involving midbrain interactions with the thalamus and cortex (Robbins et al., 1998; Détári, 2000). In contrast, focal changes in band activity that depart from this global distribution reflect underlying activity in localised processingspecific brain regions. In the EC/EO studies mentioned above, reductions in the non-alpha bands were focal: delta in frontal and lateral regions, theta in posterior regions, and beta in posterior and right hemisphere regions. These focal changes illustrate the converse of our 
arousal thesis: condition- or task-related energetics change (i.e., activation) may be accompanied by processing-specific focal EEG changes marking regional brain activity (e.g., delta and theta with visual processing: Grillon and Buchsbaum, 1986; alpha in posterior cortex in spatial vs. verbal processing: Gevins et al., 1997).

\subsection{EEG arousal and activation in healthy ageing}

This arousal/activation perspective provides a novel and theoretically-important framework for the present study. To provide a basis for EEG exploration in cognitive decline, we here examine EC/EO effects in the traditional delta, theta, alpha, and beta EEG band amplitudes in healthy ageing. Such data can be obtained easily from almost all participants, and may prove to be of clinical value. In previous work, mainly with EC conditions, delta power has been shown to decrease with increasing age (Babiloni et al., 2006; Breslau et al., 1989; Duffy et al., 1984; Gaál et al., 2010; Giaquinto and Nolfe, 1986; Polich, 1997; Sleimen-Malkoun et al., 2015; Vysata et al., 2012), as has theta power (Breslau et al., 1989; Cummins and Finnigan, 2007; Duffy et al., 1984; Polich, 1997; SleimenMalkoun et al., 2015; Vysata et al., 2012); more recently, similar findings have been reported in these bands during EO conditions (Vlahou et al., 2014; Wang et al., 2016). Alpha power has generally been shown to reduce with age (Babiloni et al., 2006; Breslau et al., 1989; Fan

et al., 2014; Polich, 1997; Sleimen-Malkoun et al., 2015; Vysata et al., 2012), while results in resting beta power have been less consistent (decrease: Breslau et al., 1989; Vysata et al., 2012; vs. increase: Duffy et al., 1984; Fan et al., 2014; Giaquinto and Nolfe, 1986; Marciani et al., 1994; Wang et al., 2016). However, Pollock et al. (1990) found no correlations of band powers with age in a group of middle-aged and elderly healthy adults (56-76 years), but the restricted age range may have obscured results. Hence our investigation sought to compare participants from discrete age groups (i.e., young university students vs. independent-living retirees). In their review, Dustman et al. (1993) reported the main age findings as alpha 
frequency slowing, and an increase in beta to about age 60 , followed by a decrease. They viewed increased beta as a favourable sign regarding health and cognitive functioning, and the increase of diffuse slow waves (delta and theta) as related to cognitive problems. This latter interpretation is compatible with van der Hiele et al.'s (2008) report that increased EC theta predicted later reductions in global cognitive and executive performance. We therefore predicted that, in contrast to the young adults, the healthy older adults would show this pattern of reduced EEG band amplitudes in delta, theta, and alpha, and an increase in beta for both EC and EO resting conditions.

Age-related topographical EEG changes may have important implications in relation to the regional activation pattern(s) in older adult populations, helping to distinguish between global arousal changes and focal changes indicating different brain processes. Unfortunately, there are few detailed reports of topographic changes with healthy ageing; most early reports used few electrodes, and more recent studies have tended to group electrodes into broad regions (e.g., Gaál et al, 2010: anterior/posterior). However, there has been some indication that delta, theta, and alpha power become more temporal with age (Babiloni et al., 2006; Breslau et al., 1989), and that alpha power remains dominantly occipital and hemispherically balanced (Giaquinto and Nolfe, 1986). Beta power increase with age was noted to be rightenhanced by Fan et al. (2014), although this study involved only 9 older subjects. It is therefore of some novelty to compare the absolute EEG band amplitude topographies of our samples, separately for each band and resting condition.

Reports of healthy ageing impacts on the EC/EO effects are also limited. EEG reactivity, or the EC to EO reduction, in alpha power is known to be diminished in dementia (van der Hiele et al., 2008), although Duffy et al. (1984) and Könönen and Partanen (1993) noted decreases with healthy ageing. Moreover, van der Hiele et al. (2008) found that, independent of diagnostic group (i.e., elderly controls, mild cognitive impairment, 
Alzheimer's disease), decreased baseline alpha EC/EO reactivity predicted poorer global cognitive and executive function at follow-up. Unfortunately, none of these EC/EO reactivity studies included topographic analysis. In the context of these sparse reports, it is important to investigate EC/EO changes in the EEG of healthy young and older groups.

With a focus on topographic aspects that can inform us about arousal/activation interpretations of these effects, the major novelty of this contribution is its placement in a theoretical context that integrates electrophysiology and behaviour. Such clarification of normal EEG changes in healthy ageing may provide theoretically-supported benchmarks to assist our understanding of the basis for cognitive dysfunction in age-related mild cognitive impairment and dementia, and provide markers of wellness in our ageing populations.

\section{Methods}

\subsection{Participants}

Participants in the Young adult group were 20 university students (5 males, 15 females) from the School of Psychology who participated voluntarily as one means of satisfying a course requirement. Their mean age was 20.4 (range 18.8-25.6) years, and all were self-reported as being right handed. The Older group consisted of 20 sex- and handedness-matched adults living independently in a Wollongong retirement resort community, with mean age 68.2 (range 59.8-74.8) years. They were recruited via a flyer and received $\mathrm{A} \$ 40$ in recompense for their voluntary participation. All subjects were screened for self-reported neurological disorders, head injury, learning disability and psychiatric conditions. They were required to abstain from caffeine and other psychoactive substances for at least $2.5 \mathrm{~h}$ prior to the testing session; older participants were required to report all current medication use and dosage. The older adults also completed a cognitive screening instrument, the Rowland Universal Dementia Assessment Scale (RUDAS; Storey et al., 2004), scoring a mean of 28.0 out of 30 (range 24-30), all above the cut-off for possible 
cognitive impairment (22).

This study was carried out in accordance with the Declaration of Helsinki. The protocol was approved by the Joint University of Wollongong/South East Sydney and Illawarra Area Health Service Human Research Ethics Committee. Written informed consent was obtained from all participants prior to participation.

\subsection{Physiological recording}

EEG was continuously recorded from A2 and 19 scalp sites using an electrode cap with tin electrodes, referenced to A1. Vertical electro-oculogram (EOG) was recorded from tin electrodes placed above and below the left eye, and horizontal EOG was recorded from electrodes beyond the outer canthi. Care was taken to balance the impedances at A1 and A2, and all impedances were below $10 \mathrm{k} \Omega$. Data were sampled continuously at $1000 \mathrm{~Hz}$ with a gain of 500, and recorded DC-30 Hz for offline analysis by a Neuroscan Synamps 2 system using Neuroscan Acquire software (Compumedics, Version 4.3.1).

\subsection{Procedure}

When participants arrived the experimental procedure was explained, they read an information sheet, signed the consent form, and completed a simple screening questionnaire. Older participants completed the RUDAS (Storey et al., 2004) in another session within 1 week of their EEG session. Participants were seated in an air-conditioned room, and fitted with the physiological measurement equipment. Prior to the experiment each participant completed a brief EOG calibration task that involved making a series of vertical and horizontal eye movements, and eye blinks. They then began a number of laboratory activities that began with resting EC followed by EO baseline periods of 3 min each. During the EO condition, participants were instructed to visually fixate on a small cross presented on a computer screen in front of them.

\subsection{Data extraction}


The continuous EEG was EOG corrected using the Revised Aligned-Artefact Average (RAAA) procedure of Croft and Barry (2000), and then digitally re-referenced to linked ears. The EEG data from each 3 min segment (EC, EO) were divided into 90 sequential 2 s epochs. These were baselined across their duration, and rejected if activity at any scalp site exceeded $\pm 100 \mu \mathrm{V}$ at any time. Each accepted epoch was subjected to a Discrete Fourier Transform (DFT) with a 10\% Hanning window. A correction (of 1.05) was applied to compensate for this window. At each electrode, absolute amplitudes in the delta $(0.5-3.5 \mathrm{~Hz})$, theta $(4.0-7.5$ $\mathrm{Hz})$, alpha $(8.0-13.0 \mathrm{~Hz})$ and beta $(13.5-24.0 \mathrm{~Hz})$ bands were calculated, and averaged across epochs. Such amplitude measures are increasingly preferred over the traditional power measures, which often need logarithmic or other transformations to reduce their skew (e.g., Barry et al., 2011). This shift from power to amplitude has been implemented in studies from our lab for some years - such as EEG involvement in the Orienting Reflex (Barry et al., 2012), and EEG-ERP brain-dynamics (Barry, 2009; Barry et al., 2014; De Blasio et al., 2013), and is becoming more widespread in the literature (e.g., Mathewson et al., 2015; Breska and Deouell, 2017).

\subsection{Statistical analyses}

EEG data were averaged in 9 regions: left frontal (Fp1, F3, F7), midline frontal (Fz), right frontal (Fp2, F4, F8), left central (T7, C3), midline central $(\mathrm{Cz})$, right central $(\mathrm{T} 8, \mathrm{C} 4)$, left posterior $(\mathrm{P} 7, \mathrm{P} 3, \mathrm{O} 1)$, midline posterior $(\mathrm{Pz})$ and right posterior $(\mathrm{P} 8, \mathrm{P} 4, \mathrm{O} 2)$ for each Group (Young, Older) and Condition (EO, EC). EEG amplitudes in these nine topographic regions were analysed separately for each band. Each analysis included a Sagittal factor and a Lateral factor (i.e., a four-way mixed MANOVA was used: Group $\times$ Condition $\times$ Sagittal $\times$ Lateral), with repeated measures on the last three factors. The Sagittal factor included planned contrasts that compared the frontal regions $(\mathrm{F})$ with the posterior regions $(\mathrm{P})$, and the central regions $(\mathrm{C})$ with the mean of the frontal and posterior regions $(\mathrm{F} / \mathrm{P})$. The Lateral 
factor included planned contrasts that compared activity in the left hemisphere (L) with the right $(\mathrm{R})$, and the midline region $(\mathrm{M})$ with the mean of the two hemispheres $(\mathrm{L} / \mathrm{R})$. These contrasts and their interactions allow precise identification of all possible topographic patterns over the nine regions, and provide a systematic analysis that optimises the MANOVA approach (O'Brien and Kaiser, 1985). As all contrasts were planned independently of the data, and there were no more of them than the degrees of freedom for effect, Bonferroni-type adjustments of $\alpha$ were not required (Tabachnick and Fidell, 2013). Unless otherwise stated, all $F$ tests have $(1,38)$ degrees of freedom, and effects approaching significance $(.05 \leq p<.10)$ are reported but not discussed.

From our perspective that global alpha is an inverse measure of arousal, and that the major effect of opening the eyes is to increase cortical arousal, the EC to EO change in alpha at each electrode should be correlated with its EC resting value. Topographic variation in the changes in other bands, previously interpreted as focal changes in brain activity associated with visual processing, should result in smaller correlations. To examine this we computed Pearson correlations of the within-group means across subjects at each site, using scatterplots with trend lines for illustration.

\section{Results}

\subsection{Overall spectral distribution}

The numbers of accepted epochs for the Young group ranged from 75 to $90(M=$ 86.2, $S D=4.8)$ in $\mathrm{EC}$, and 79 to $90(M=88.3, S D=3.4)$ in $\mathrm{EO}$; corresponding numbers in the Older group ranged from 84 to $90(M=89.5, S D=1.4)$ for EC and 69 to $90(M=87.8$, $S D=5.6$ ) for EO. Because there were significantly more EC epochs in the Older than Young group ( $t$-test for unequal variances: $t=-2.9$, two-tailed $p=.008)$, the numbers of accepted Go and NoGo epochs were added as covariates in the MANOVAs described in section 2.5. The spectral distributions at $\mathrm{Fz}, \mathrm{Cz}, \mathrm{Pz}$, and the mean across $\mathrm{O} 1$ and $\mathrm{O} 2$, are shown for each group 
in Figure 2, with $95 \%$ Confidence Intervals indicated by the error bars. Amplitudes as a function of frequency are shown for EC on the left and EO on the right. Band limits are indicated at $\mathrm{Cz}$ for EC activity. The mean weighted peak alpha frequency for each group and condition is shown on the $\mathrm{O} 1 / \mathrm{O} 2$ spectra. Generally speaking, the young group shows more activity than the older group in delta, theta, and alpha; the reverse is apparent for beta. It can be seen that the age difference is significant in different bands at different electrodes, but this single-electrode perspective is relatively underpowered compared with the planned topographic analyses. The peak alpha frequency was higher for Young $(M=9.68, S D=0.64$ $\mathrm{Hz})$ than Older $(M=9.18, S D=0.81 \mathrm{~Hz})$ participants $\left(F=7.97, p=.008, \eta_{\mathrm{p}}{ }^{2}=.17\right)$, but did not differ with hemisphere or Condition; there were no interactions.

Fig. 2 about here

\subsection{Delta}

Figure 3 (top left) shows that across Group and Condition, delta was dominant in the midline $(\mathrm{M}>\mathrm{L} / \mathrm{R}: F=356.95, p<.001)$ and right hemisphere $(\mathrm{L}<\mathrm{R}: F=13.28, p<.001)$, with a vertex maximum $(\mathrm{C}>\mathrm{F} / \mathrm{P} \times \mathrm{M}>\mathrm{L} / \mathrm{R}: F=59.56, p<.001$; see Table 1 for the full statistics including effect size. To save space, statistics for the following contrasts are provided only in Table 1. In delta, the regression over covariates was significant for Condition and Group. The headmaps of the top row show that across Group delta activity was reduced in EO relative to EC conditions, more so in the posterior region, particularly hemispherically, less so centrally, and somewhat more so in the right hemisphere, particularly centrally (see top right headmap). Across Condition, the left column of Figure 3 shows that there was a significant global delta reduction in older compared to young adults, more so in the midline and posterior regions, and in the posterior hemispheres, and somewhat so in the right hemisphere and at the vertex (see bottom left headmap). The reduced delta in older than young adults was significantly greater for EC than EO in frontoparietal regions, as is apparent 
in the bottom row of Figure 3; that is, the older (cf. young) adults showed substantial frontoparietal focal delta activity with opening of the eyes (see bottom right headmap).

Table 1 and Fig. 3 about here

\subsection{Theta}

The mean headmap over Group and Condition (top left, Figure 4) shows that theta was dominant in the midline, particularly at the vertex, in the right hemisphere, and in the posterior region, more so hemispherically (also see Table 1). In theta, the regression over covariates was nonsignificant for both Condition and Group. The headmaps in Figure 4 (top row) show that across Group there was significantly less theta activity globally in EO than EC conditions, particularly in the posterior (more so on the right) and midline regions (particularly at the vertex), but less so centrally and in the left hemisphere (see top right headmap). Across Condition, the older adults had relatively less theta globally when compared to the young (left row, Figure 4), somewhat more so posteriorly, and significantly so in the midline (more so frontally) and right hemisphere (more so posteriorly). As apparent in the bottom row of Figure 4, the relative reduction in theta activity in older (cf. young) adults was somewhat less in EO compared with EC in the right hemisphere, and significantly more so in the posterior region, particularly on the right. That is, the older (cf. young) adults showed substantial parietal focal theta activity with opening of the eyes (see bottom right headmap).

Fig. 4 about here

\subsection{Alpha}

As shown in Figure 5 (top left), mean alpha across Group and Condition was strongly posterior (note the relative central reduction in Table 1), and midline dominant (particularly centrally) with a right hemisphere bias; the posterior dominance was enhanced in the right hemisphere and reduced in the midline (see Table 1). In alpha, the regression over covariates 
was significant for Condition, but not Group. Across Group, the top row of Figure 5 shows significant alpha reductions in EO cf. EC. This decrease was larger posteriorly, somewhat more so in the hemispheres, and particularly so on the right, and in the midline and right hemispheric regions, but was reduced across the central region, particularly in the hemispheres (see top right headmap). The bottom left headmap of Figure 5 shows that, across Condition, the older adults had somewhat less alpha globally compared to the young adults; significant reductions were found in the right hemisphere and posterior region (particularly in the hemispheres), and in the posterior right region, but smaller reductions were seen centrally. Also apparent in the bottom row of Figure 5, the older (cf. young) reduction in alpha activity was somewhat reduced globally in EO compared with EC, and significantly so in posterior and posterior hemispheric regions; and less so in central and central hemispheric regions. The topography of this reactivity is similar to the EC alpha.

Fig. 5 about here

\subsection{Beta}

The top left headmap of Figure 6 shows that the mean beta, over Group and Condition, was centroparietal (note the dual underlining of effect and statistic in Table 1; see table notes), and midline with a right hemispheric bias. These effects interacted differently, with the central enhancement larger in the midline (vertex maximum) and the posterior dominance greater in the hemispheres (see Table 1). In beta, the regression over covariates was significant for Condition, but not Group. Across Group, the top right headmap of Figure 6 shows significant beta reductions in EO relative to EC conditions globally, but also particularly in the midline and posterior regions, and in the posterior hemispheres. Across Condition (left column headmaps), there was significantly more beta globally in older than young adults (again note the underlining in Table 1), somewhat more so in the left hemisphere and parietal left region, and significantly so frontocentrally and in the frontal 
hemispheres, as seen in the bottom left headmap. As is apparent in the bottom row of Figure 6, the greater beta activity in older than young adults was significantly greater in EO compared with EC in the posterior region and reduced in the central region (see bottom right headmap). That is, the older (cf. young) adults showed significant parietal focal beta activity with opening of the eyes.

Fig. 6 about here

\subsection{Alpha and arousal}

Figure 7 shows scatterplots of the EC to EO reduction (i.e., reactivity) in mean EEG band amplitude at each electrode as a function of its EC value, with each point representing one electrode, in either the Young or Older group. A regression line through the origin tests the hypothesis that the reactivity is proportional to the EC amplitude at each electrode. Over both groups, correlations over electrodes ranged from $r(36)=-.41$ for beta to $r(36)=-.88$ for alpha; all were significant $(p<.01$; one-tailed). However, the correlations for delta, theta, and beta were significantly smaller than for alpha $(N=38, Z \geq 1.86, p<.05$; one-tailed). Within alpha, although the correlation was somewhat smaller for the Older $(r(17)=-.83)$ than the Young group $(r(17)=-.91)$, these values did not differ significantly $(N=19, Z=0.99, p=$ .16; one-tailed).

Fig. 7 about here

\section{Discussion}

Across groups, the topographies of the band amplitudes used here are broadly consistent with the power data in EC and EO resting conditions reported by Barry et al. (2007, 2009a). All bands are midline dominant, with a right hemisphere elevation. This right hemisphere elevation is associated with a lower level of cortical activation, particularly in alpha (Barry et al., 2007), and is expected from the left hemisphere dominance of the right- 
handed participants. The Young data are similar to our previous results from a separate university sample comparable in age (Barry et al., 2007), recorded with a different system some 10 years earlier, showing more posterior distributions in the upper than lower bands.

\subsection{Main and topographic effects of age}

In general, the Older group had smaller amplitudes than the Young group in resting delta and theta, somewhat so in alpha, with larger amplitudes in beta. These main findings are compatible with Duffy et al. (1984) and Polich (1997), with the frequency transition from marked slow wave reductions, through small alpha reductions, to the increase in beta activity. They contradict a report by Breslau et al. (1989) who found a reduction in all bands in resting (EC) and alert (EO, listening to a story) EEGs in their old (mean age 70) compared with a young (mean age 23) control group. Reduced beta in the elderly has been associated with cognitive impairment and reduced general health (Dustman et al., 1993), and the beta elevation here supports the independent living and functioning status of our Older adult group.

Topographically, the Older (cf. Young) group had reduced delta in the midline and posterior region, particularly in the posterior hemispheres. They also had reduced theta activity in the midline, particularly frontally, and in the right hemisphere, particularly

posteriorly, generally confirming and extending the reduced resting-state EO theta previously reported in healthy cognitive ageing (Cummins and Finnigan, 2007). The significant reduction in alpha activity in the older group was prominent in the posterior region, particularly on the right. In contrast, the beta activity increase in the older group was significantly larger in frontocentral areas and the frontal hemispheres. These novel topographic findings confirm the value of full-cap data analysis in ageing studies.

Our finding of reduced alpha frequency in the Older group is also broadly consistent with the Dustman et al. (1993) review. Note that this is a relatively small effect (Giaquinto 
and Nolfe, 1986; Polich, 1997), and thus may not be apparent with few epochs or poor frequency resolution, such as in many early studies.

\subsection{Changes with EC/EO}

Across groups, the EO (cf. EC) condition was associated with reduced EEG amplitude in each band, as similarly reported in young adults by Barry et al. (2007) and in children by Barry et al. (2009a) using power measures. The reductions were larger in the posterior region for each band. In delta and theta, the difference in topography of the reactive change compared with the EC baseline condition indicates a substantial contribution of focal activity reflecting regional visual processing. The posterior alpha reduction in EO compared to EC generally reflected the EC alpha topography, suggesting mainly an arousal change. The beta reduction was also notable in the midline region, and there was some frontal increase.

These reductions in EEG band activity from EC to EO conditions differed with age. In delta and theta, the reactivity was smaller in the Older than Young group; particularly in delta in non-central sites, and in theta in posterior sites. These slow wave reductions did not match the EC topography in either group. In alpha, reductions were similar to the EC topography, and somewhat smaller globally in the Older group, as in Könönen and Partanen (1993), and particularly so in posterior regions, echoing Duffy et al. (1984). The beta reactivity change was smaller in the Older group in the non-central sites, quite different from the EC topography. That is, the EEG reactivity associated with opening the eyes was smaller in our Older adult group, suggesting a general reduction of EEG reactivity with healthy ageing. There was also a significant shift from the arousal reactivity shown in beta by the Young group to more focal processing in the Older group, suggesting activation of differential processing.

\subsection{Global alpha decrease marks arousal change}

With opening the eyes, the decrease in alpha at each electrode was highly correlated 
with the EC amplitude at that electrode. This indicates that the reactivity in alpha was global across the scalp, supporting the conceptualisation of the change in alpha as largely an arousal increase, perhaps reflecting the uncoupling of extensive thalamocortical interactions supporting visual processing (Gevins et al., 1997; Klimesch, 1999). This effect was significantly stronger for alpha than the other bands, confirming the unique alpha/arousal nexus in contrast to the more-focal changes in the other bands (Barry et al., 2007). Decreased localised delta and theta are generally associated with stimulus processing, and hence indicate increased activation in the EO condition associated with unstructured visual processing of the immediate environment in the absence of a given task. Studies from our laboratory have previously demonstrated this connection in children (Barry et al., 2009a) and young adults (Barry et al., 2007). The present study thus confirms the nature of this effect in young adults, and extends it to well-functioning older adults, suggesting that this interpretation of the effect of eyes-opening on alpha is of considerable generality across the lifespan. Interestingly, this link between the EC to EO change and the EC amplitude at each electrode was somewhat weaker in the Older than Young group, but not significantly so. This may suggest that the alpha/arousal nexus reduces somewhat with increasing age, a possibility worth exploring in future studies. We have also recently reported age-related changes in task related processing, as indexed by ERPs, in this sample of participants (Barry et al., 2016). The role of arousal/activational differences in such performance changes with normal ageing is of interest, and future investigations may therefore benefit by assessing if the relationships between the ongoing EEG and ERP outcomes (e.g., EEG phase effects: Barry et al., 2004b, 2014; EEG amplitude effects: De Blasio et al., 2013) remain stable across the lifespan. Such aspects of event-related EEG dynamics (for reviews see Palva and Palva, 2007, 2011) may offer alternative insights into the EEG of ageing than can be explored here.

\subsection{Older adults maintain arousal and activation}


Volf and Gluhih (2011) have speculated that age-related changes in "background" or resting EEG activity provide the context for compensatory mechanisms in ageing "which may be somehow related to both mobilization of larger resources ensuring cognitive activity and reorganization of cortical networks in the areas prone to age-related physiological changes" (p. 566). Interestingly, Deiber et al. (2013) have similarly linked such EEG topographic shifts in different bands during active cognitive tasks to the possible engagement of circuits at different frequencies during attention. Also, reduced task-related beta has been linked to poorer task performance (Gola et al., 2012), and Gola et al. (2013) related such beta reductions to difficulty in activation and deficits in sustained attention. Here, the focal posterior reduction and frontal-right increase in beta activity with the EC to EO transition can be interpreted as indicating focal processing changes additional to those shown by the Young group. That is, the general age differences interpreted in light of the arousal/activation thesis suggest that the older adults generally maintain reactivity to environmental change, with the addition of further processing resources, even in resting conditions. This may contribute to healthy/high functioning older individuals being able to match task performance (including everyday general functioning) of young persons. However, here we examined only resting conditions, so this novel hypothesis must remain tentative.

\subsection{Limitations}

Although matched on size and sex by the Young group, the Older group size was small and not balanced on sex, being a convenience sample from the retirement community. It has long been established that sex differences in EEG profiles occur throughout the lifespan (Langrová et al., 2012; Wada et al., 1994), and exploring such differences in ageing could be instructive. Larger groups, balanced and matched on sex, would also improve the generalisability of the findings. Further, while the present older participants were screened to avoid the problems of mild cognitive impairment, the inclusion in future studies of a wider 
range of neuropsychological assessment instruments for both the older and young participants, and/or the incorporation of these and other populations with pathological ageing, would refine the information available.

In addition, motivational aspects could differ between the young student volunteers and the older volunteer group. Although such differences would be expected to impact task performance rather than resting EEG measures, future studies should attempt to estimate motivation levels and utilise these for better control.

\subsection{Conclusion}

This study provides useful information in relation to establishing the EEG profile of healthy ageing, and how it is affected by the simple manipulation of opening the eyes. This resting state study generated a wealth of new information in regard to the amplitude and topography of the traditional EEG bands, and their changes from young adults to healthy

older volunteers. We suggest that healthy older adults, compared with young adults, maintain reactivity of their energetics system(s) and harness additional focal brain activity, even in resting conditions, and that this may provide the basis for their maintenance of perceptual and cognitive performance in later years (Barry et al., 2016). As these data do not require a task, they can be recorded with little difficulty from populations with mild cognitive impairment and dementia, and may provide valuable insight into the arousal, activation, and task-specific brain contribution to pathological ageing. Indeed, it is likely that many clinics already have these data at hand, and due to the ease of analysis we encourage their exploration in this context. Replication and elaboration of the present findings in older samples, including both healthy and cognitively-impaired participants, could eventually provide a simple clinical screening tool useful in clarifying the onset of mild cognitive impairment, and help early detection of the dementias that plague old age. 


\section{Acknowledgement}

We thank Prof. Craig Gonsalvez for his contributions to this project. We also thank The Illawarra Retirement Trust (IRT) and the management of IRT Links Seaside for their kind assistance in providing facilities and encouraging resident participation in this project. 


\section{References}

Adrian, E.D., Matthews, B.H.C., 1934. The Berger rhythm: Potential changes from the occipital lobes in man. Brain 57, 355-385.

Babiloni, C., Binetti, G., Cassarino, A, Dal Forno, G, Del Percio, C, Ferreri, F, Ferri, R, Frisoni, G, Galderisi, S, Hirata, K, Lanuzza, B, Miniussi, C, Mucci, A, Nobili, F, Rodriguez, G., Romani, G.L., Rossini, P.M., 2006. Sources of cortical rhythms in adults during physiological aging: A multicentric EEG study. Hum Brain Mapp 27, 162-172. doi: 10.1002/hbm.20175

Barry, R.J., 2004. Stimulus significance effects in habituation of the phasic and tonic orienting reflex. Integ Physiol Behav Science 39, 166-179. doi: 10.1007/BF02734437

Barry, R.J., 2009. Evoked activity and EEG phase resetting in the genesis of auditory Go/NoGo ERPs. Biol Psychol 80, 292-299. doi: 10.1016/j.biopsycho.2008.10.009

Barry, R.J., Clarke, A.R., Johnstone, S.J., 2011. Caffeine and opening the eyes have additive effects on resting arousal measures. Clin Neurophysiol 122, 2010-2015. doi: 10.1016/j.clinph.2011.02.036

Barry, R.J., Clarke, A.R., Johnstone, S.J., Brown, C.R., 2009a. EEG differences in children between eyes-closed and eyes-open resting conditions. Clin Neurophysiol 120, 18061811. doi: 10.1016/j.clinph.2009.08.006

Barry, R.J., Clarke, A.R., Johnstone, S.J., Brown, C.R., Bruggemann, J.M., van Rijbroek, I., 2009b. Caffeine effects on resting-state arousal in children. Int J Psychophysiol 73, 355-361. doi: 10.1016/j.ijpsycho.2009.05.012

Barry, R.J., Clarke, A.R., Johnstone, S.J., Magee, C.A., Rushby, J.A., 2007. EEG differences between eyes-closed and eyes-open resting conditions. Clin Neurophysiol 118, 27652773. doi: 10.1016/j.clinph.2007.07.028

Barry, R.J., Clarke, A.R., Johnstone, S.J., McCarthy, R., Selikowitz, M., 2009c. 
Electroencephalogram $\theta / \beta$ ratio and arousal in attention-deficit/hyperactivity disorder: Evidence of independent processes. Biol Psychiatry 66, 398-401. doi: 10.1016/j.biopsych.2009.04.027

Barry, R.J., Clarke, A.R., Johnstone, S.J., Rushby, J.A., 2008. Timing of caffeine's impact on autonomic and central nervous system measures: Clarification of arousal effects. Biol Psychol 77, 304-316. doi: 10.1016/j.biopsycho.2007.11.002

Barry, R.J., Clarke, A.R., McCarthy, R., Selikowitz, M., Rushby, J.A., Ploskova, E., 2004a. EEG differences in children as a function of resting-state arousal level. Clin Neurophysiol 115, 402-408. doi: 10.1016/S1388-2457(03)00343-2

Barry, R.J., De Blasio, F.M., Cave, A.E., 2016. Sequential processing in young and older adults in the equiprobable auditory Go/NoGo task. Clin Neurophysiol 127, 22732285. doi: 10.1016/j.clinph.2016.02.010

Barry, R.J., De Blasio, F.M., De Pascalis, V., Karamacoska, D., 2014. Preferred EEG brain states at stimulus onset in a fixed interstimulus interval equiprobable auditory Go/NoGo task: A definitive study. Int J Psychophysiol 94, 42-58. doi: 10.1016/j.ijpsycho.2014.07.005

Barry, R.J., Rushby, J.A., Johnstone, S.J., Clarke, A.R., Croft, R.J., Lawrence, C.A., 2004b. Event-related potentials in the auditory oddball as a function of EEG alpha phase at stimulus onset. Clin Neurophysiol 115, 2593-2601. doi: 10.1016/j.clinph.2004.06.004

Barry, R.J., Rushby, J.A., Wallace, M.J., Clarke, A.R., Johnstone, S.J., Ilinka, Z., 2005. Caffeine effects on resting-state arousal. Clin Neurophysiol 116, 2693-2700. doi: 10.1016/j.clinph.2005.08.008

Barry, R.J., Sokolov, E.N., 1993. Habituation of phasic and tonic components of the orienting reflex. Int J Psychophysiol 15, 39-42. doi: 10.1016/0167-8760(93)90093-5

Barry, R.J., Steiner, G.Z., De Blasio, F.M., 2012. Event-related EEG time-frequency analysis 
and the orienting reflex to auditory stimuli. Psychophysiology 49, 744-755. doi: 10.1111/j.1469-8986.2012.01367.x

Başar, E., Schürmann, M., 1999. "Cross-Modality experiments in humans" in Brain Function and Oscillations: II. Integrative brain function, neurophysiology and cognitive processes, ed. E. Başar (Germany: Springer), 143-153.

Berger, H., 1933. Über das Elektrenkephalogramm des Menschen. Arch F Psychiat 98, 231254.

Breska, A., Deouell, L.Y., 2017. Neural mechanisms of rhythm-based temporal prediction: Delta phase-locking reflects temporal predictability but not rhythmic entrainment. PLoS Biol 15:e2001665. doi: 10.1371/journal.pbio.2001665

Breslau, J., Starr, A., Sicotte, N., Higa, J., Buchsbaum, M.S., 1989. Topographic EEG changes with normal aging and SDAT. Electroencephal Clin Neurophysiol 72, 281289. doi: 10.1016/0013-4694(89)90063-1

Chapman, R.M., Armington, J.C., Bragdon, H.R., 1962. A quantitative survey of kappa and alpha EEG activity. Electroencephal Clin Neurophysiol 14, 858-868. doi: $10.1016 / 0013-4694(62) 90136-0$

Croft, R.J., Barry, R.J., 2000. EOG correction of blinks with saccade coefficients: A test and revision of the aligned-artefact average solution. Clin Neurophysiol 111, 444-451. doi: 10.1016/S1388-2457(99)00296-5

Cummins, T.D.R., Finnigan, S., 2007. Theta power is reduced in healthy cognitive aging. Int J Psychophysiol 66, 10-17. doi: 10.1016/j.ijpsycho.2007.05.008

De Blasio, F.M., Barry, R.J., Steiner, G.Z., 2013. Prestimulus EEG amplitude determinants of ERP responses in a habituation paradigm. Int J Psychophysiol 89, 444-450. doi: 10.1016/j.ijpsycho.2013.05.015

Deiber, M.-P., Ibañez, V., Missonnier, P., Rodriguez, C., Giannakopoulos, P., 2013. Age- 
associated modulaitons of cerebral oscillatory patterns related to attention control. NeuroImage 82, 531-546. doi: 10.1016/j.neuroimage.2013.06.037

Détári, L., 2000. Tonic and phasic influence of basal forebrain unit activity on the cortical EEG. Behav Brain Res 115, 159-170. doi: 10.1016/S0166-4328(00)00256-4

Duffy, F.H., Albert, M.S., McAnulty, G., Garvey, A.J., 1984. Age-related differences in brain electrical activity of healthy subjects. Ann Neurol 16, 430-438. doi: 10.1002/ana.410160403

Dustman, R.E., Shearer, D.E., Emmerson, R.Y., 1993. EEG and event-related potentials in normal aging. Prog Neurobiol 41, 369-401.

Fan, J.C., Cheung, R.T., Chu, L.W., Fung, P.C.W., Chang, C.Q., Sik, H.H., Zhang, M.M., Xie, B.J., Hung, Y.S., Gao, J.L., 2014. Age-related changes of EEG and its source in resting state. 19th International Conference on Digital Signal Processing (DSP). doi: 10.1109/ICDSP.2014.6900774

Fisch, B.J., 1999. Fisch and Spehlmann's EEG primer: Basic principles of digital and analog EEG. Amsterdam: Elsevier.

Gaál, Z.A., Boha, R., Stam, C.J., Molnár, M., 2010. Age-dependent features of EEGreactivity - Spectral, complexity, and network characteristics. Neurosci Lett 479, 7984. doi: 10.1016/j.neulet.2010.05.037

Gale, A., Coles, M., Boyd, E., 1971. Variation in visual input and the occipital EEG: II. Psychon Science 23, 99-100. doi: 10.3758/BF03336026

Gevins, A., Smith, M.E., McEvoy, L., Yu, D., 1997. High resolution EEG mapping of cortical activation related to working memory: Effects of task difficulty, type of processing, and practice. Cerebral Cortex 7, 374-385. doi: 10.1093/cercor/7.4.374

Giaquinto, S., Nolfe, G., 1986. The EEG in the normal elderly: A contribution to the interpretation of aging and dementia. Electroencephal Clin Neurophysiol 63, 540-546. 
doi: 10.1016/0013-4694(86)90141-0

Glass, A., Kwiatkowski, A.E., 1970. Power spectral density changes in the EEG during mental arithmetic and eye-opening. Psychologische Forschung 33, 85-90. doi: 10.1007/BF00424979

Gola, M., Kamiński, J., Brzezicka, A., Wróbel, A., 2012. Beta band oscillations as a correlate of alertness - Changes in aging. Int J Psychophysiol 85, 62-67. doi: 10.1016/j.ijpsycho.2011.09.001

Gola, M., Magnuski, M., Szumska, I., Wróbel, A., 2013. EEG beta band activity is related to attention and attentional deficits in the visual performance of elderly subjects. Int $J$ Psychophysiol 89, 334-341. doi: 10.1016/j.ijpsycho.2013.05.007

Grillon, C., Buchsbaum, M.S., 1986. Computed EEG topography of response to visual and auditory stimuli. Electroenceph Clin Neurophysiol 63, 42-53. doi: 10.1016/00134694(86)90061-1

Hardle, W., Gasser, T., Bacher, P., 1984. EEG responsiveness to eye opening and closing in mildly retarded children compared to a control group. Biol Psychol 18, 185-199.

Jasper, H.H., 1936. Cortical excitatory state and variability in human brain rhythms. Science 83, 259-260. doi: 10.1126/science.83.2150.259

Klimesch, W., 1999. EEG alpha and theta oscillations reflect cognitive and memory performance: A review and analysis. Brain Res Rev 29, 169-195. doi: 10.1016/S01650173(98)00056-3

Kőnőnen, M., Partanen, J.V., 1993. Blocking of EEG alpha activity during visual performance in healthy adults - A quantitative study. Electroenceph Clin Neurophysiol 87, 164-166. doi: 10.1016/0013-4694(93)90122-C

Langrová, J., Kremláček, J., Kuba, M., Kubová, Z., Szanyi, J., 2012. Gender impact on electrophysiological activity of the brain. Physiol Res 61 Suppl 2, S119-S127. 
Legewie, H., Simonova, O., Creutzfeldt, O.D., 1969. EEG changes during performance of various tasks under open and closed eyes conditions. Electroenceph Clin Neurophysiol 27, 470-479. doi: 10.1016/0013-4694(69)90187-4

Marciani, M.G., Maschio, M., Spanedda, F., Caltagirone, C., Gigli, G.L., Bernardi, G., 1994. Quantitative EEG evaluation in normal elderly subjects during mental processes: Agerelated changes. Int J Neurosci 76, 131-140. doi: 10.3109/00207459408985998

Mathewson, K.J., Hashemi, A., Sheng, B., Sekuler, A.B., Bennett, P.J., Schmidt, L.A., 2015. Regional electroencephalogram (EEG) alpha power and asymmetry in older adults: A study of short-term test-retest reliability. Front Aging Neurosci 7:177. doi: 10.3389/fnagi.2015.00177

O'Brien, R.G., Kaiser, M.K., 1985. MANOVA method for analyzing repeated measures designs: An extensive primer. Psychol Bull 97, 316-333. doi: 10.1037/00332909.97.2.316

Palva, S., Palva, J.M., 2007. New vistas for alpha-frequency band oscillations. Trends Neurosci 30, 150-158. doi: 10.1016/j.tins.2007.02.001

Palva, S., Palva, J.M., 2011. Functional roles of alpha-band phase synchronization in local and large-scale cortical networks. Front Psychol 2:204. doi: 10.3389/fpsyg.2011.00204

Polich, J., 1997. EEG and ERP assessment of normal aging. Electroencephal Clin Neurophysiol 104, 244-256. doi: 10.1016/S0168-5597(97)96139-6

Pollock, V.E., Schneider, L.S., Lyness, S.A., 1990. EEG amplitudes in healthy, late-middleaged and elderly adults: normality of the distributions and correlations with age. Electroencephal Clin Neurophysiol 75, 276-288. doi: 10.1016/0013-4694(90)90106-T

Pribram, K.H., McGuinness, D., 1975. Arousal, activation, and effort in the control of attention. Psychol Rev 82, 116-149. doi: 10.1037/h0076780 
Robbins, T.W., Granon, S., Muir, J.L., Durantou, F., Harrison, A., Everitt, B.J., 1998. Neural systems underlying arousal and attention: Implications for drug abuse. Ann N Y Acad Sci 846, 222-237. doi: 10.1111/j.1749-6632.1998.tb09740.x

Sleimen-Malkoun, R., Perdikis, D., Müller, V., Blanc, J.-L., Huys, R., Temprado, J.-J., Jirsa, V.K., 2015. Brain dynamics of aging: Multiscale variability of EEG signals at rest and during an auditory oddball task. eNeuro 2:0067. doi: 10.1523/ENEURO.006714.2015

Smith, J.R., 1938. The Electroencephalogram during normal infancy and childhood: II. The nature of the growth of the alpha waves. J Gen Psychol 53, 455-469. doi: $10.1080 / 08856559.1938 .10533821$

Storey, J., Rowland, J., Basic, D., Conforti, D., Dickson, H., 2004. The Rowland Universal Dementia Assessment Scale (RUDAS): A multicultural cognitive assessment scale. Int Psychogeriatr 16, 13-31. doi: 10.1017/S1041610204000043

Tabachnick, B.G., Fidell, L.S., 2013. Using Multivariate Statistics (6th ed). England: Pearson Education Limited.

VaezMousavi, S.M., Barry, R.J., Rushby, J.A., Clarke, A.R., 2007a. Evidence for differentiation of arousal and activation in normal adults. Acta Neurobiol Exp 67, 179186.

VaezMousavi, S.M., Barry, R.J., Rushby, J.A., Clarke, A.R., 2007b. Arousal and activation effects on physiological and behavioral responding during a continuous performance task. Acta Neurobiol Exp 67, 461-470.

VaezMousavi, S.M., Barry, R.J., Clarke, A.R., 2009. Individual differences in task-related activation and performance. Physiol Behav 98, 326-330. doi: 10.1016/j.physbeh.2009.06.007

van der Hiele, K., Bollen, E.L.E.M., Vein, A.A., Reijntjes, R.H.A.M., Westendorp, R.G.J., 
van Buchem, M.A., Middelkoop, H.A.M., van Dijk, J.G., 2008. EEG markers of future cognitive performance in the elderly. J Clin Neurophysiol 25, 83-89. doi: 10.1097/WNP.0b013e31816a5b25

Vlahou, E.L., Thurm, F., Kolassa, I.-T., Schlee, W., 2014. Resting-state slow wave power, healthy aging and cognitive performance. Sci Rep 4:5101. doi: 10.1038/srep05101

Volavka, J., Matoušek, M., Roubíček, J., 1967. Mental Arithmetic and Eye Opening. An EEG frequency analysis and GSR study. Electroenceph Clin Neurophysiol 22, 174-176. doi: 10.1016/0013-4694(67)90158-7

Volf, N.V., Gluhih, A.A., 2011. Background cerebral electrical activity in healthy mental aging. Hum Physiol 37, 559-567. doi: 10.1134/S0362119711040207

Vysata, O., Kukal, J., Prochazka, A., Pazdera, L., Valis, M., 2012. Age-related changes in the energy and spectral composition of EEG. Neurophysiology 44, 63-67. doi: $10.1007 / \mathrm{s} 11062-012-9268-\mathrm{y}$

Wada, Y., Takizawa, Y., Jiang, Z.Y., Yamaguchi, N., 1994. Gender differences in quantitative EEG at rest and during photic stimulation in normal young adults. Clin Electroencephalogr 25, 81-85. doi: 10.1177/155005949402500209

Wang, H., McIntosh, A.R., Kovacevic, N., Karachalios, M., Protzner, A.B., 2016. Agerelated multiscale changes in brin signal variability in pre-task versus post-task resting-state EEG. J Cognitive Neurosci 28, 971-984.doi: 10.1162/jocn_a_00947 


\section{AROUSAL}

\section{AROUSAL vS. ACTIVATION}

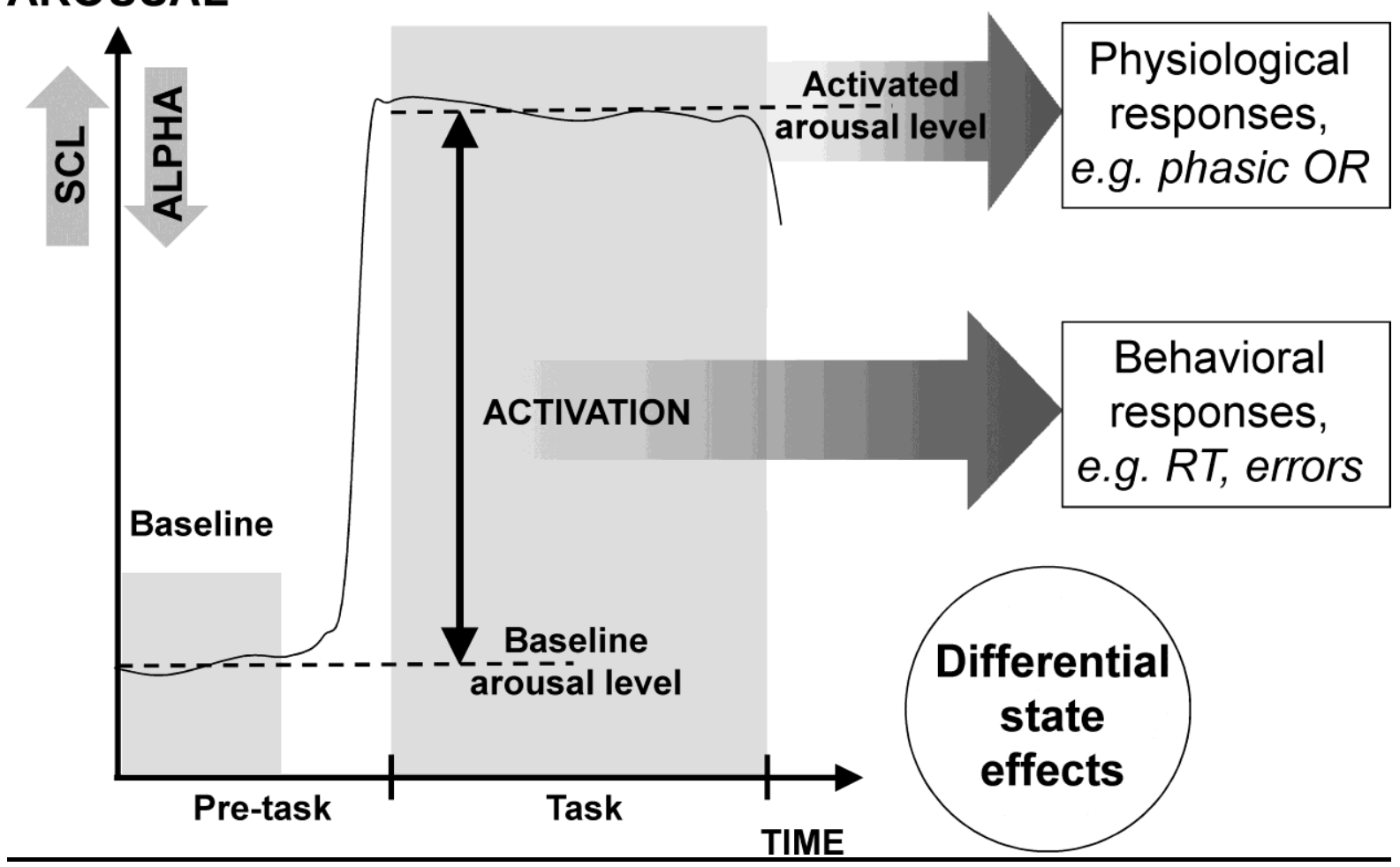

Figure 1. Arousal and activation are separable aspects of the energetics dimension. Arousal is the energy level of a particular state, such as shown here for a baseline and task. The change in arousal level due to an increase in processing demands is the activation due to that task or increased processing state. These energetics levels can be measured directly by SCL or (inversely) by alpha band activity. Activation may or may not be accompanied by focal changes in EEG bands marking the utilisation of processing-specific brain regions. 
EYES CLOSED
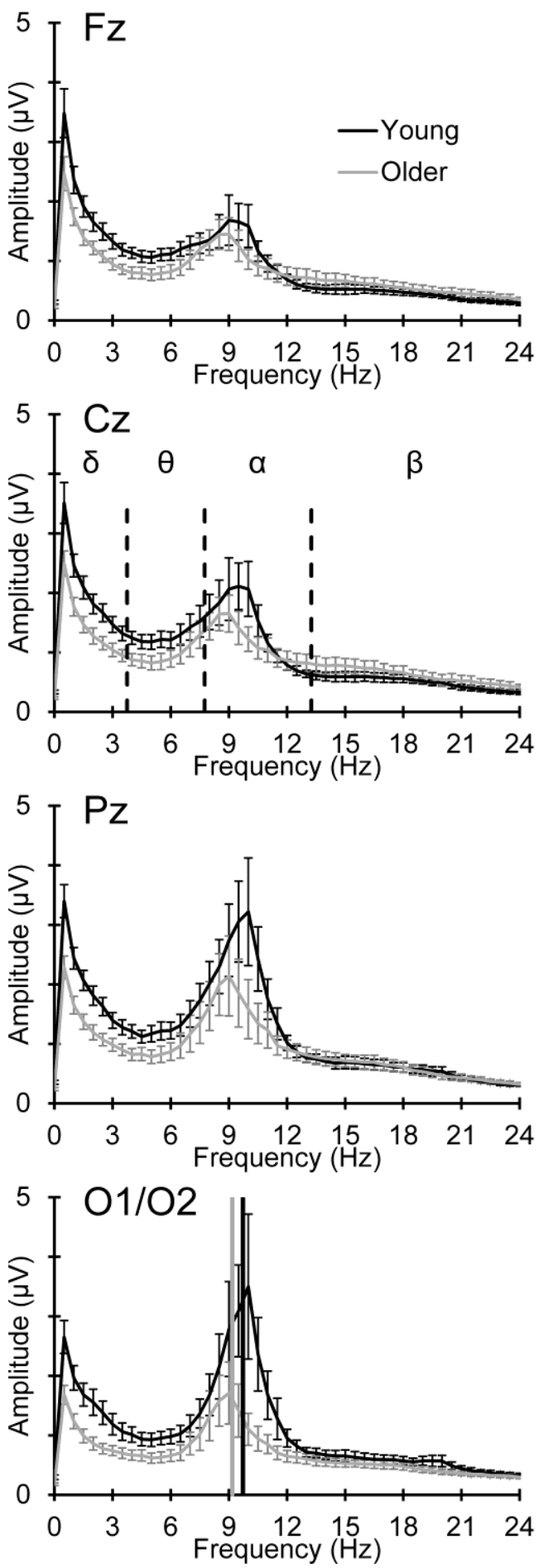

EYES OPEN
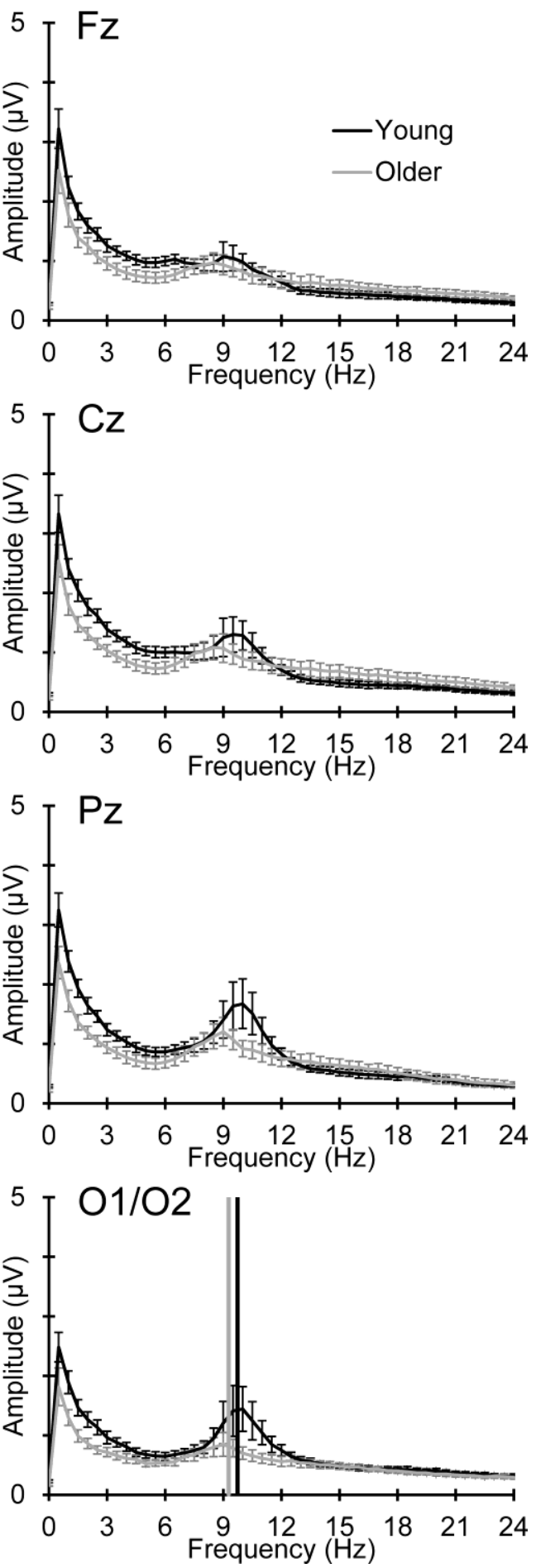

Figure 2. Eyes closed (left) and eyes open (right) EEG spectra at the midline sites and the O1/O2 mean for the young and older adult groups. The assessed EEG bands are indicated at $\mathrm{Cz}$ for eyes closed, and the vertical lines in the $\mathrm{O} 1 / \mathrm{O} 2$ plots indicate the mean peak alpha frequencies for the young (black) and older (grey) adult groups. Error bars indicate 95\% Confidence Intervals. 


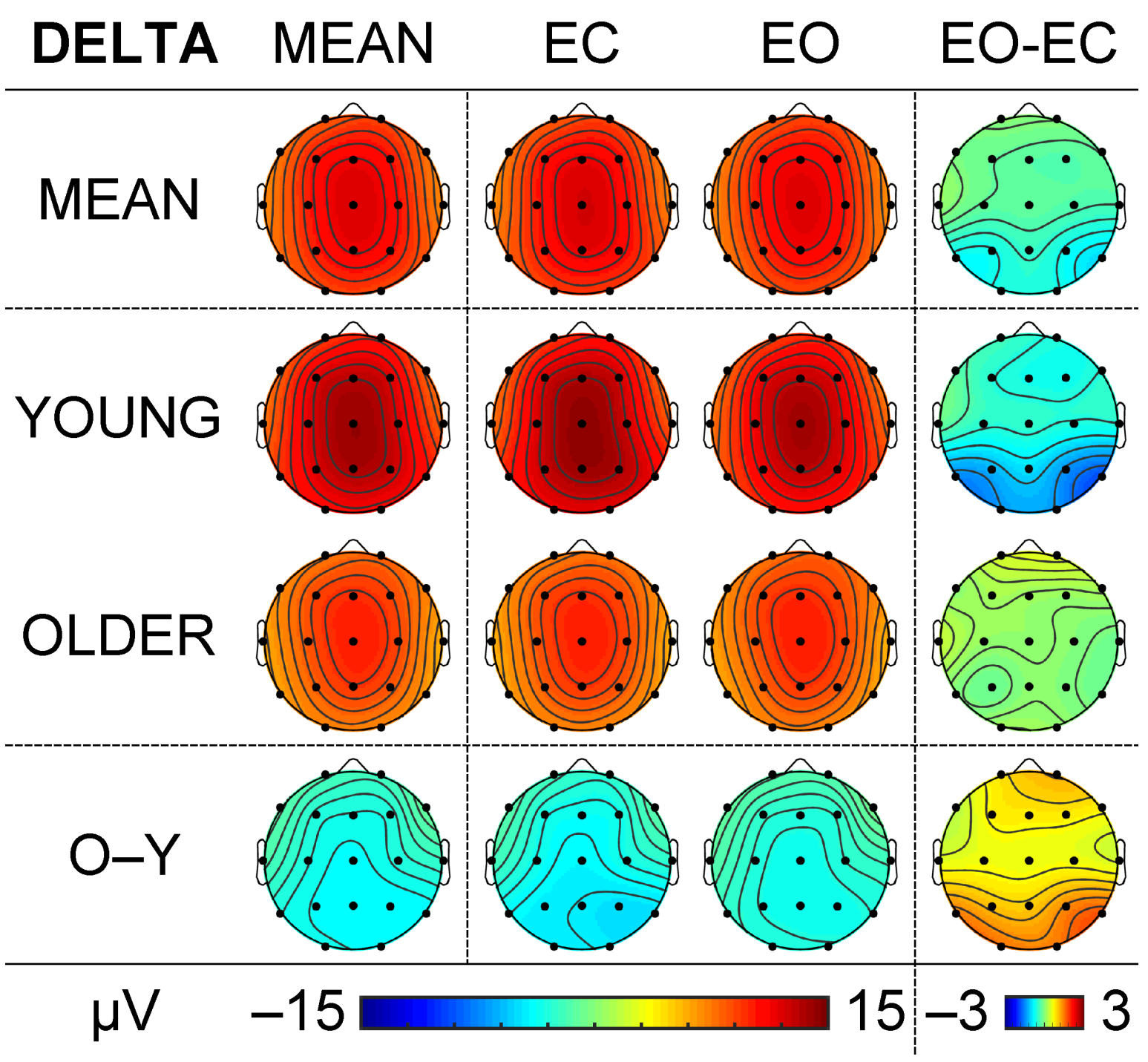

Figure 3. Topographic effects of EC vs. EO for the Young and Older groups in the Delta band. These are available in colour online. 


\section{THETA MEAN EC EO EO-EC}

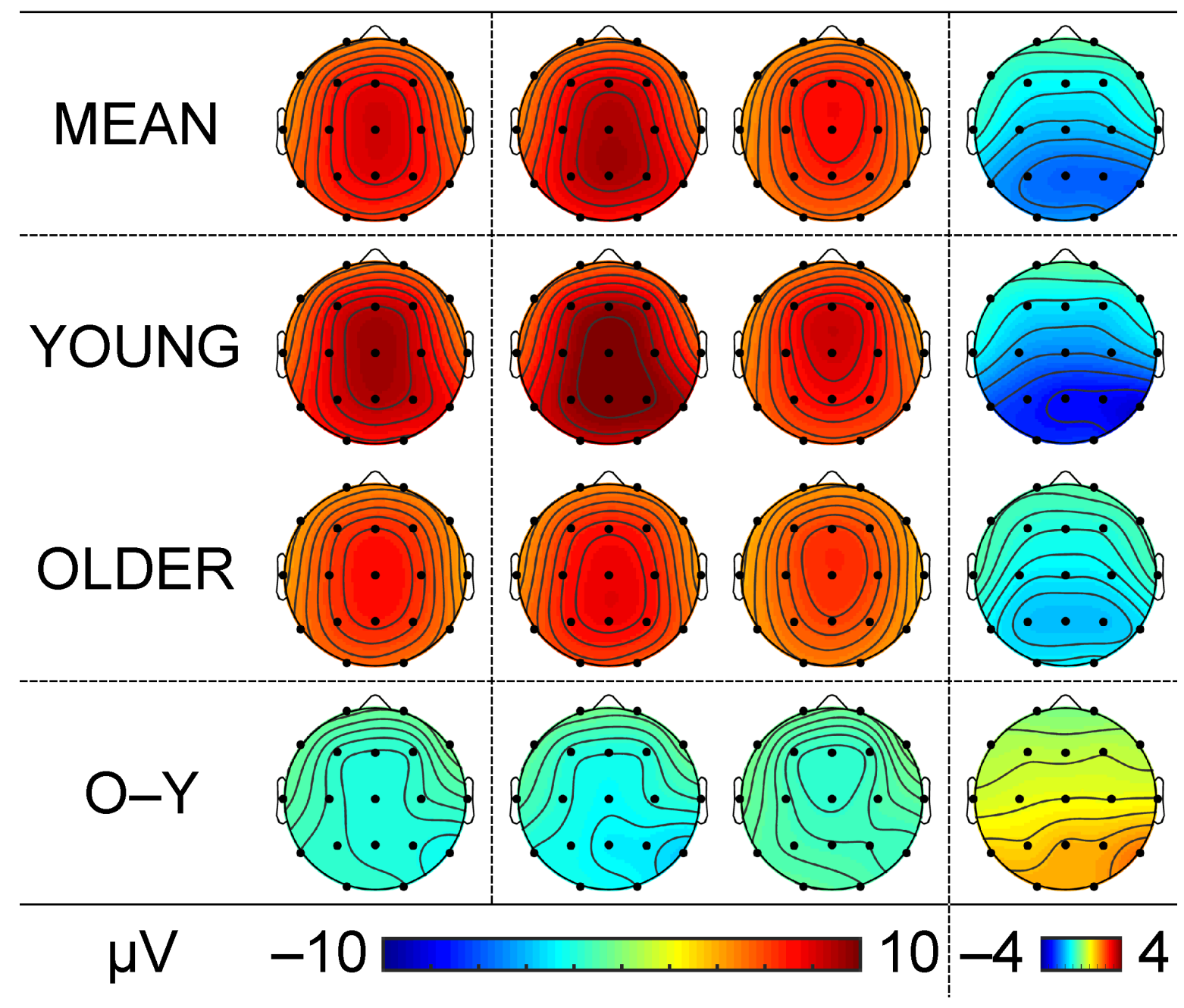

Figure 4. Topographic headmaps for each condition and group in the Theta band. These are available in colour online. 


\section{ALPHA MEAN EC EO EO-EC}

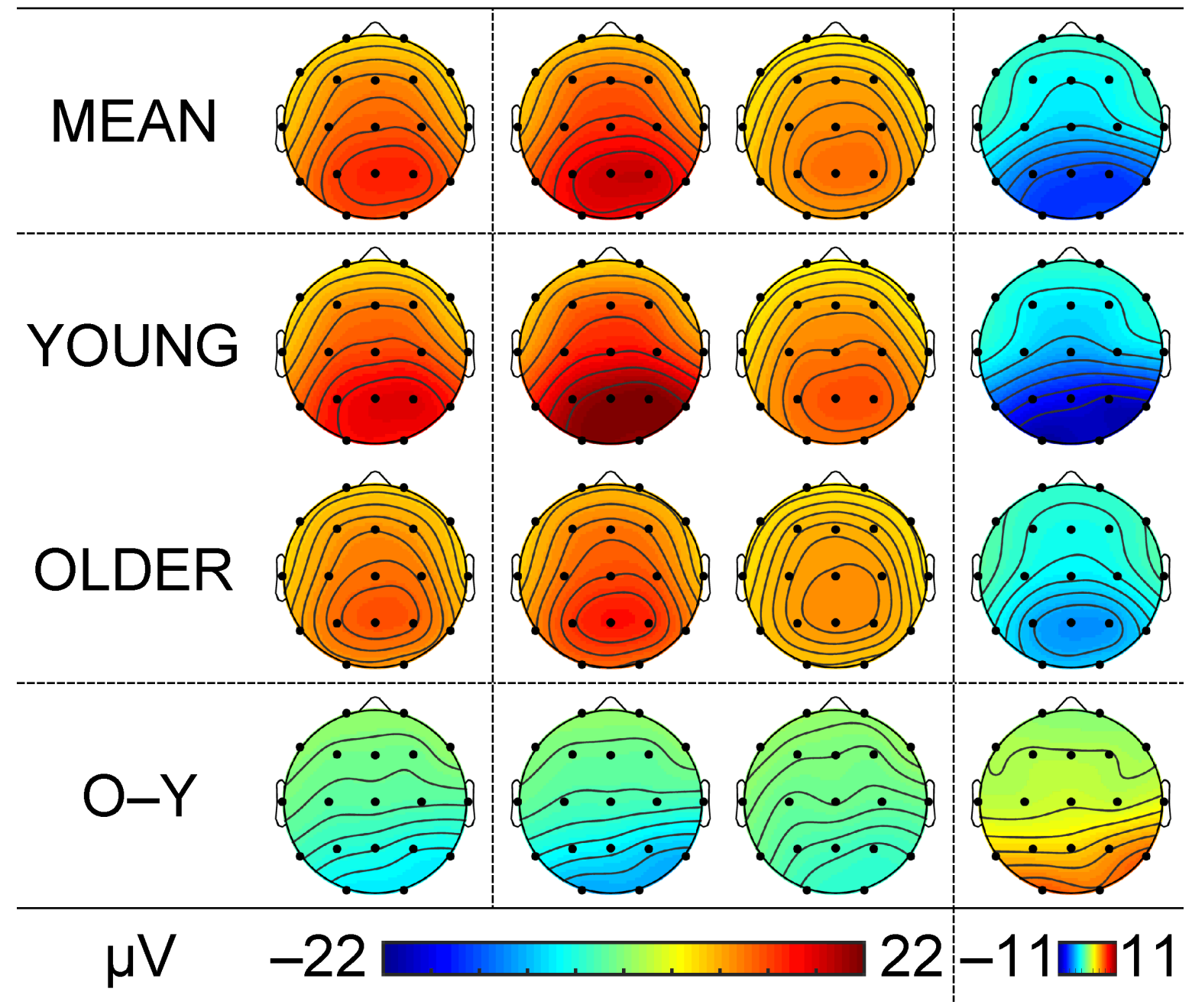

Figure 5. Effects of condition and group on the topography of Alpha amplitude. These are available in colour online. 


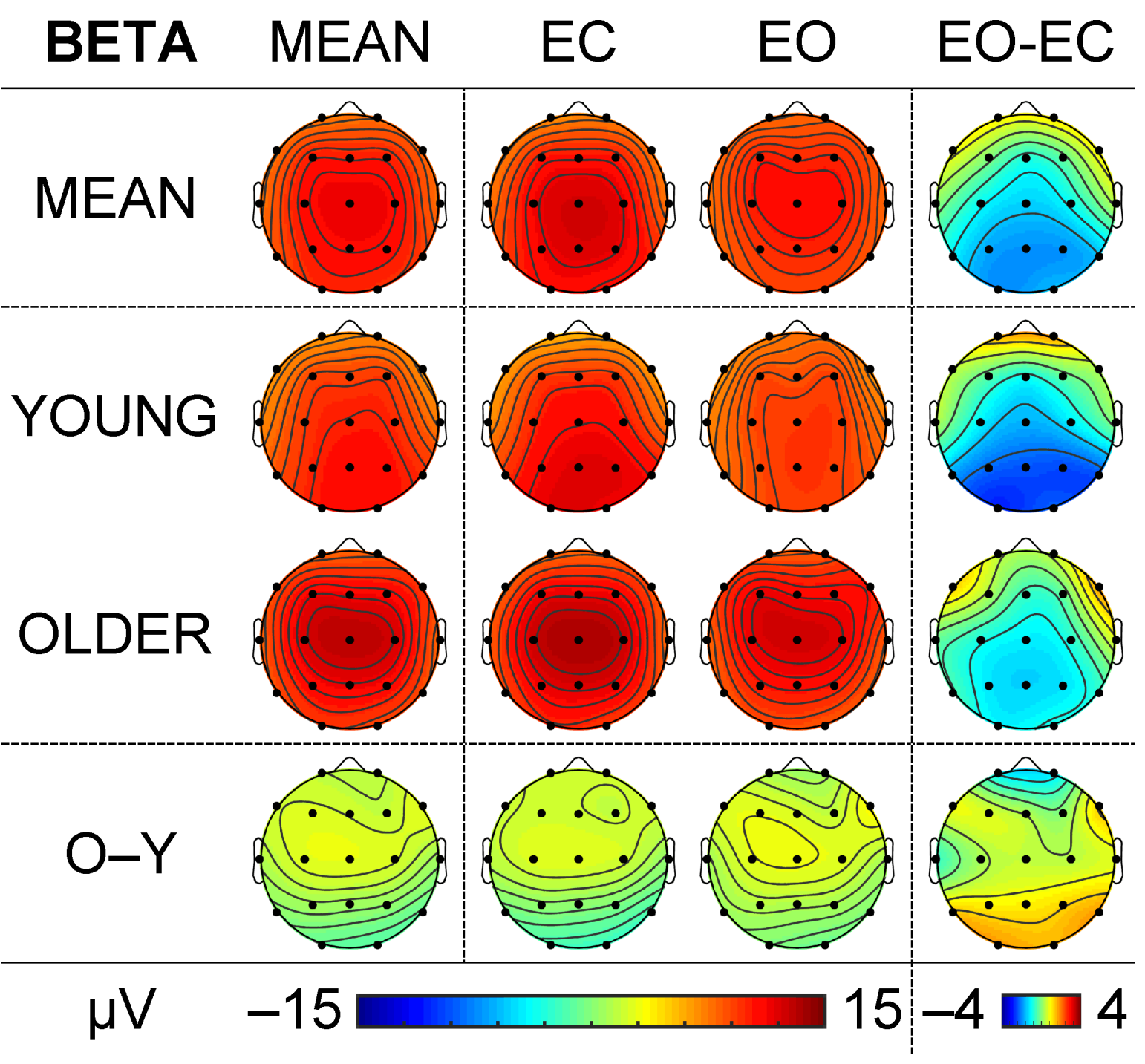

Figure 6. Topographic effects of condition and group in the Beta band. These are available in colour online. 

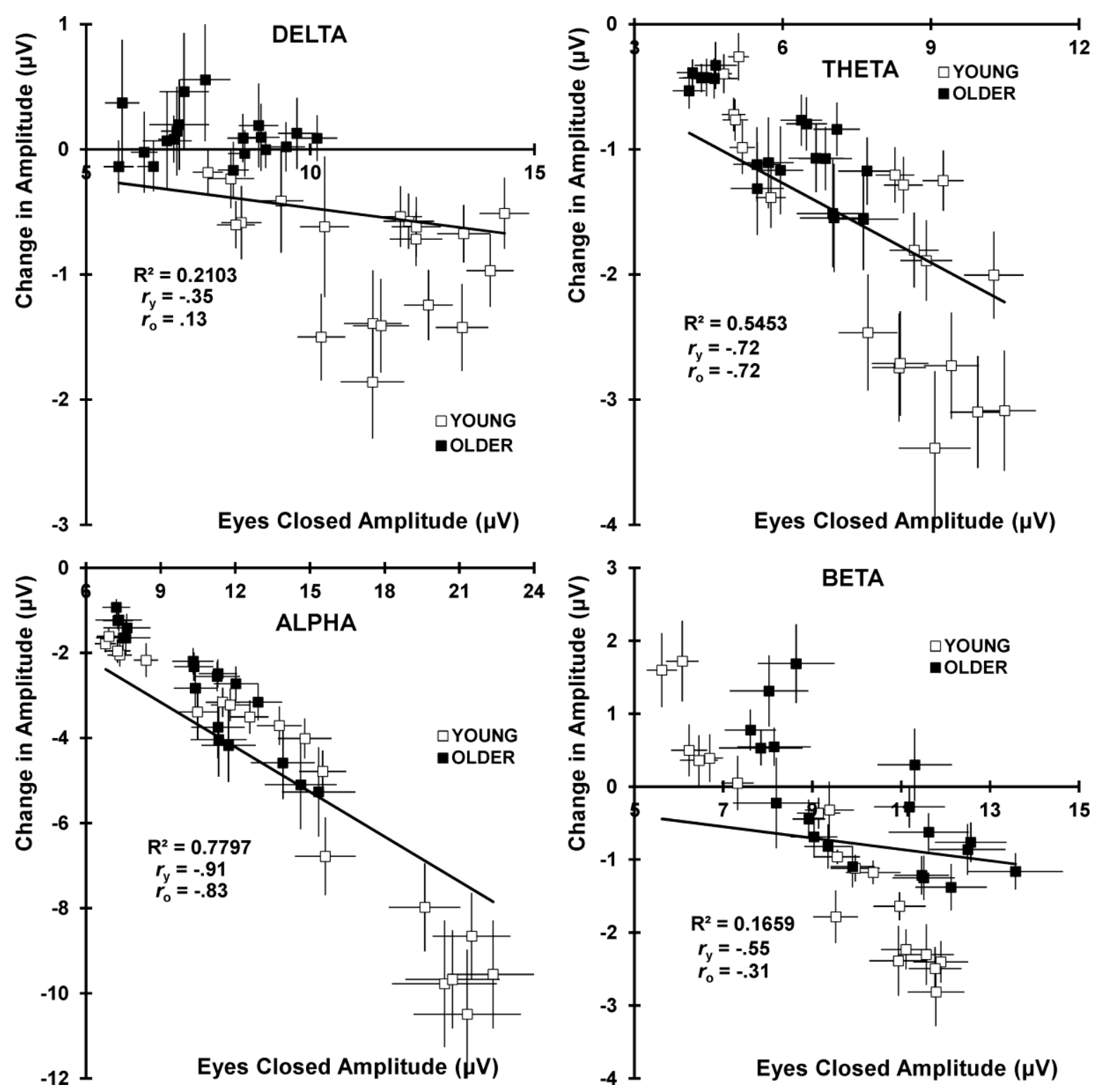

Figure 7. Scatter plots of the eyes-open (EO) minus eyes-closed (EC) change in mean amplitude (i.e., reactivity) plotted as a function of EC mean amplitude for each electrode for each group, separately for each band. Each point represents one electrode. The linear trend lines are fitted across the groups for each assessed band, with the coefficient of determination, $\mathrm{R}^{2}$, shown. Separate correlations for Young and Older groups, $r_{\mathrm{y}}$ and $r_{\mathrm{o}}$, are also indicated. 


\begin{tabular}{|c|c|c|c|c|c|c|c|c|c|c|c|c|}
\hline \multirow[b]{2}{*}{ Effect } & \multicolumn{3}{|c|}{ DELTA } & \multicolumn{3}{|c|}{ THETA } & \multicolumn{3}{|c|}{ ALPHA } & \multicolumn{3}{|c|}{ BETA } \\
\hline & $F$ & $p$ & $\eta_{\mathrm{p}}^{2}$ & $F$ & $p$ & $\eta_{\mathrm{p}}^{2}$ & $F$ & $p$ & $\eta_{\mathrm{p}}{ }^{2}$ & $F$ & $p$ & $\eta_{\mathrm{p}}^{2}$ \\
\hline \multicolumn{13}{|l|}{ Topography } \\
\hline \multicolumn{13}{|l|}{ Sagittal } \\
\hline $\mathrm{F}<\mathrm{P}$ & & & & 17.57 & $<.001$ & .32 & 86.52 & $<.001$ & .69 & 16.07 & $<.001$ & .30 \\
\hline $\mathrm{C}<\mathrm{F} / \mathrm{P}$ & & & & & & & 11.24 & .002 & .23 & $\underline{6.19}$ & .017 & .14 \\
\hline \multicolumn{13}{|l|}{ Lateral } \\
\hline $\mathrm{L}<\mathrm{R}$ & 13.28 & $<.001$ & .26 & 8.70 & .005 & .19 & 15.87 & $<.001$ & .29 & 4.36 & .044 & .10 \\
\hline$M>L / R$ & 356.95 & $<.001$ & .90 & 258.09 & $<.001$ & .87 & 147.58 & $<.001$ & .80 & 49.99 & $<.001$ & .57 \\
\hline \multicolumn{13}{|l|}{ Sagittal $\times$ Lateral } \\
\hline $\mathrm{F}<\mathrm{P} \times \mathrm{L}<\mathrm{R}$ & & & & & & & 7.25 & .010 & .16 & & & \\
\hline $\mathrm{F}<\mathrm{P} \times \mathrm{M}<\mathrm{L} / \mathrm{R}$ & & & & 36.41 & $<.001$ & .49 & 4.95 & .032 & .12 & 4.37 & .043 & .10 \\
\hline $\mathrm{C}>\mathrm{F} / \mathrm{P} \times \mathrm{M}>\mathrm{L} / \mathrm{R}$ & 59.56 & $<.001$ & .61 & 50.49 & $<.001$ & .57 & 6.94 & .012 & .15 & 20.27 & $<.001$ & .35 \\
\hline Regression $^{\dagger}$ & 13.14 & .001 & .26 & & & & 9.55 & .004 & .21 & 8.69 & .006 & .19 \\
\hline $\mathrm{EC}>\mathrm{EO}^{\dagger}$ & 5.45 & .025 & .13 & 55.65 & $<.001$ & .60 & 142.25 & $<.001$ & .79 & 29.21 & $<.001$ & .44 \\
\hline \multicolumn{13}{|l|}{ Condition $\times$ Topography } \\
\hline $\mathrm{EC}>\mathrm{EO} \times \mathrm{F}<\mathrm{P}$ & 7.06 & .011 & .16 & 43.68 & $<.001$ & .53 & 63.45 & $<.001$ & .63 & 69.79 & $<.001$ & .65 \\
\hline $\mathrm{EC}>\mathrm{EO} \times \mathrm{C}<\mathrm{F} / \mathrm{P}$ & 6.14 & .018 & .14 & 8.93 & .005 & .19 & 38.66 & $<.001$ & .50 & & & \\
\hline $\mathrm{EC}>\mathrm{EO} \times \mathrm{L}<\mathrm{R}$ & 3.70 & .062 & .09 & 7.94 & .008 & .17 & 9.88 & .003 & .21 & & & \\
\hline $\mathrm{EC}>\mathrm{EO} \times \mathrm{M}>\mathrm{L} / \mathrm{R}$ & & & & 28.94 & $<.001$ & .43 & 42.31 & $<.001$ & .53 & 98.11 & $<.001$ & .72 \\
\hline $\mathrm{EC}>\mathrm{EO} \times \mathrm{F}<\mathrm{P} \times \mathrm{L}<\mathrm{R}$ & & & & 10.26 & .003 & .21 & 6.19 & .017 & .14 & & & \\
\hline $\mathrm{EC}>\mathrm{EO} \times \mathrm{F}<\mathrm{P} \times \mathrm{M}<\mathrm{L} / \mathrm{R}$ & 5.20 & .028 & .12 & & & & 3.57 & .066 & .09 & 31.21 & $<.001$ & .45 \\
\hline $\mathrm{EC}>\mathrm{EO} \times \mathrm{C}>\mathrm{F} / \mathrm{P} \times \mathrm{L}<\mathrm{R}$ & 4.03 & .052 & .10 & & & & & & & & & \\
\hline $\mathrm{EC}>\mathrm{EO} \times \mathrm{C}>\mathrm{F} / \mathrm{P} \times \mathrm{M}>\mathrm{L} / \mathrm{R}$ & & & & 6.19 & .017 & .14 & 23.99 & $<.001$ & .39 & & & \\
\hline Regression $^{\dagger}$ & 14.18 & .001 & .28 & & & & & & & & & \\
\hline${\underline{\text { Young }}>\text { Older }^{\dagger}}^{-1}$ & 31.23 & $<.001$ & .46 & 9.35 & .004 & .20 & 3.69 & .062 & .09 & $\underline{4.41}$ & .043 & .10 \\
\hline \multicolumn{13}{|l|}{ Group $\times$ Topography } \\
\hline Young $>$ Older $\times \mathrm{F}<\mathrm{P}$ & 7.24 & .011 & .16 & 3.80 & .059 & .09 & 19.72 & $<.001$ & .34 & 14.16 & .001 & .27 \\
\hline Young $>$ Older $\times \mathrm{C}<\mathrm{F} / \mathrm{P}$ & & & & & & & 4.91 & .033 & .11 & 11.65 & .002 & .23 \\
\hline Young $>$ Older $\times \mathrm{L}<\mathrm{R}$ & 2.89 & .097 & .07 & 5.08 & .030 & .12 & 7.56 & .009 & .17 & 3.00 & .092 & .07 \\
\hline Young $>$ Older $\times \mathrm{M}>\mathrm{L} / \mathrm{R}$ & 10.52 & .002 & .22 & 7.42 & .010 & .16 & & & & & & \\
\hline Young $>$ Older $\times \mathrm{F}<\mathrm{P} \times \mathrm{L}<\mathrm{R}$ & & & & 7.32 & .010 & .16 & 5.76 & .021 & .13 & 2.99 & .092 & .07 \\
\hline Young $>$ Older $\times \mathrm{F}<\mathrm{P} \times \mathrm{M}<\mathrm{L} / \mathrm{R}$ & 6.71 & .013 & .15 & 10.72 & .002 & .22 & 6.70 & .014 & .15 & 6.37 & .016 & .14 \\
\hline Young $>$ Older $\times \mathrm{C}>\mathrm{F} / \mathrm{P} \times \mathrm{M}>\mathrm{L} / \mathrm{R}$ & 3.32 & .076 & .08 & & & & & & & & & \\
\hline \multicolumn{13}{|l|}{ Group $\times$ Condition } \\
\hline Young $>$ Older $\times \mathrm{EC}>\mathrm{EO}^{\dagger}$ & & & & & & & 3.21 & .081 & .08 & & & \\
\hline \multicolumn{13}{|l|}{ Group $\times$ Condition $\times$ Topography } \\
\hline Young $>$ Older $\times \mathrm{EC}>\mathrm{EO} \times \mathrm{F}<\mathrm{P}$ & & & & 9.06 & .005 & .19 & 11.86 & .001 & .24 & 6.10 & .018 & .14 \\
\hline Young $>$ Older $\times \mathrm{EC}>\mathrm{EO} \times \mathrm{C}<\mathrm{F} / \mathrm{P}$ & 7.45 & .010 & .16 & & & & 4.74 & .036 & .11 & 5.62 & .023 & .13 \\
\hline Young $>$ Older $\times \mathrm{EC}>\mathrm{EO} \times \mathrm{L}<\mathrm{R}$ & & & & 4.09 & .050 & .10 & & & & & & \\
\hline Young $>$ Older $\times \mathrm{EC}>\mathrm{EO} \times \mathrm{F}<\mathrm{P} \times \mathrm{L}<\mathrm{R}$ & & & & 4.92 & .033 & .11 & & & & & & \\
\hline Young $>$ Older $\times \mathrm{EC}>\mathrm{EO} \times \mathrm{F}<\mathrm{P} \times \mathrm{M}<\mathrm{L} / \mathrm{R}$ & & & & & & & 9.43 & .004 & .20 & & & \\
\hline Young $>$ Older $\times \mathrm{EC}>\mathrm{EO} \times \mathrm{C}<\mathrm{F} / \mathrm{P} \times \mathrm{M}<\mathrm{L} / \mathrm{R}$ & & & & & & & 7.06 & .011 & .16 & & & \\
\hline
\end{tabular}

Note: Underlined statistical results indicate a reversal of the corresponding underlined effect or interaction. The reversal of any pair of directional indicators within a single effect is statistically equivalent; e.g., $\mathrm{F}<\mathrm{P} \times \mathrm{M}<\mathrm{L} / \mathrm{R} \equiv \mathrm{F}>\mathrm{P} \times \mathrm{M}>\mathrm{L} / \mathrm{R}$. Significant effects are indicated with bold $p$ values. $\mathrm{EC}=$ Eyes Closed; $\mathrm{EO}=$ Eyes Open; $\mathrm{F}=\mathrm{Frontal} ; \mathrm{C}=\mathrm{Central} ; \mathrm{P}=\mathrm{Parietal} ; \mathrm{L}=\mathrm{Left} ; \mathrm{M}=$ Midline; $R=$ Right. ${ }^{\dagger}$ Denotes tests with $(1,37)$ degrees of freedom due to covariate. 